\title{
Geospatial Associations Between Tobacco Retail Outlets and Current Use of Cigarettes and e-Cigarettes among Youths in Texas
}

\section{Adriana Pérez ${ }^{1 *}$, Lung-Chang Chien ${ }^{2}$, Melissa B Harrell ${ }^{3}$, Keryn E Pasch ${ }^{4}$, Udoka C Obinwa ${ }^{5}$ and Cheryl L Perry ${ }^{6}$}

${ }^{1}$ Department of Biostatistics and Data Sciences, The University of Texas Health Science Center at Houston-UTHealth, School of Public Health, USA ${ }^{2}$ Department of Environmental and Occupational Health, University of Nevada, Las Vegas, School of Community Health Sciences, USA

${ }^{3}$ Department of Epidemiology, Human Genetics and Environmental Sciences, The University of Texas Health Science Center at Houston-UTHealth, School of Public Health, USA

${ }^{4}$ Department of Kinesiology and Health Education, College of Education at The University of Texas at Austin, USA

${ }^{5}$ Research Assistant, The University of Texas Health Science Center at Houston- UTHealth, Michael \& Susan Dell Center for Healthy Living, Austin, USA

${ }^{6}$ Department of Health Promotion and Behavioral Sciences at UTHealth, University of Texas Health Science Center at Houston, School of Public Health, Austin Campus, USA

\begin{abstract}
Introduction: To identify the geospatial association between the presence of tobacco retail outlets (TRO) around schools' neighborhoods, and current use of cigarettes and e-cigarettes among adolescents in four counties in Texas.

Methods: Students in grades 6, 8 and 10th were surveyed in their schools in 2014-2015. The schools' addresses was geocoded to determine the presence of at least one TRO within half a mile of the school. Two outcomes were considered: past 30-day use of (a) cigarettes and (b) e-cigarettes. Bayesian structured additive regression models and Kriging methods were used to estimate the geospatial associations between the presence of TRO and use in three counties: Dallas/Tarrant, Harris, and Travis.
\end{abstract}

Results: We observed a geospatial association between the presence of TRO around the schools and current use of cigarettes in the eastern area of Dallas County and in the southeastern area of Harris County. Also, a geospatial association between the presence of TRO around the schools and current use of e-cigarettes was observed in the entire Tarrant County and in the northeastern area of Harris County.

Conclusions: There were geospatial associations between the presence of TRO around some schools and cigarette/e-cigarette use among students, but this association was not consistent across all the counties. More research is needed to determine why some areas are at higher risk for this association.

Keywords: Geospatial associations; Tobacco retail outlets; Kriging, Bayesian regression; Cigarettes; e-Cigarettes

\section{Introduction}

Tobacco use remains an enormous public health burden and the leading cause of preventable death around the globe [1]. Among youth, tobacco use is particularly problematic as this behavior increases the chances of addiction and continued use as adults [2-4]. With increased awareness of the dangers of tobacco use and sustained efforts to curtail smoking through local, state, and national policies, the prevalence of cigarette smoking has reduced over the past 20 years, yet many have started to use other forms of tobacco like e-cigarettes. e-Cigarettes have the potential for nicotine toxicity due to high levels of nicotine in the cartridges [5]. Comprehensive data on the long-term health effects of e-cigarettes use are currently unavailable.

Recently, several studies have examined the prevalence of cigarette and e-cigarette use in the U.S. The Population Assessment of Tobacco and Health (PATH) study in 2013-2014 assessed a representative sample of youth 12-17 years old in the U.S. [6,7]. PATH reported that while $13.4 \%$ and $10.7 \%$ were ever users of cigarettes and e-cigarettes, respectively, $4.6 \%$ and $3.1 \%$ of participants were past 30 -day users. During the academic year of 2014-2015, the Texas Adolescent Tobacco and Marketing Surveillance System (TATAMS) examined a representative sample of students enrolled in $6^{\text {th }}, 8^{\text {th }}$ and $10^{\text {th }}$ grades [8]. TATAMS reported that $10.9 \%$ and $19.5 \%$ were ever users while $3.5 \%$ and $7.4 \%$ were past 30 -day users of cigarettes and e-cigarettes respectively. TATAMS also had a higher prevalence of current use of cigarette $(5.3 \%)$ and e-cigarette (10.6\%) than PATH after the agestandardization to the PATH population.
One of the dominant channels for tobacco advertising in the U.S. is at Tobacco Retail Outlets (TRO) (e.g., ads posted at the retail location). Tobacco advertising and promotional activities at TROs motivate young people to initiate cigarette use as the advertisements create positive impressions and attitudes towards smoking [3,9]. Studies examining TRO activities in US retail outlets have reported higher cigarette marketing in stores that are more frequently visited by adolescents as opposed to those stores less frequently visited $[9,10]$. In 2003, a longitudinal study of three middle schools in California found that exposure to retail cigarette advertising was a risk factor for initiating cigarette use, susceptibility to cigarette use and smoking status [11]. Recently, recall of e-cigarette advertisements at TRO was significantly associated with adolescent e-cigarette susceptibility and use in a longitudinal study [12]. However, there is currently limited information on the association between the presence of TRO advertisement around schools and current use of e-cigarettes by youths

*Corresponding author: Pérez A, Associate Professor in the Department of Biostatistics and Data Sciences, The University of Texas Health Science Center at Houston-UTHealth, School of Public Health, USA, Tel: (512) 391-2524; E-mail: adriana.perez@uth.tmc.edu

Received September 28, 2017; Accepted October 10, 2017; Published October 18,2017

Citation: Pérez A, Chien LC, Harrell MB, Pasch KE, Obinwa UC, et al. (2017) Geospatial Associations Between Tobacco Retail Outlets and Current Use of Cigarettes and e-Cigarettes among Youths in Texas. J Biom Biostat 8: 375. doi: 10.4172/2155-6180.1000375

Copyright: ( 2017 Pérez A, et al. This is an open-access article distributed under the terms of the Creative Commons Attribution License, which permits unrestricted use, distribution, and reproduction in any medium, provided the original author and source are credited. 
in the U.S. One study looked at the association of TRO and current use of cigarettes but only in 3 middle schools in California [9]. Though certain studies have utilized Geographic Information Systems in describing the density of tobacco retail outlets, they did not examine how it influences tobacco use behavior [13-15]. Few studies have linked the presence and density of the outlets with cigarette use behavior but none has done so with e-cigarettes $[16,17]$.

The aim of the study is to examine the association of the presence of TRO around schools on adolescents' current use of cigarettes and e-cigarettes among the 2014-2015 TATAMS representative sample of students enrolled in $6^{\text {th }}, 8^{\text {th }}$ and $10^{\text {th }}$ grades in Texas. We conducted a secondary data analysis by county and our hypothesis was that students attending schools surrounded by TRO selling tobacco would have higher prevalence of current cigarette and e-cigarette use.

\section{Methods}

\section{Study design, participants and study areas}

The details of the TATAMS sampling design, sampling frame, and sampling weights were described previously with a summary presented here. TATAMS used a complex random sample of students enrolled in grades 6, 8 and 10th from five counties in Texas (Harris, Dallas/ Tarrant, Bexar, and Travis) that surround the four largest metropolitan areas in Texas (Houston, Dallas/Fort Worth, San Antonio, and Austin) [8]. The sample of schools $(n=5)$ were too few to conduct a geospatial analysis in Bexar County. Schools and surrounding TRO in Dallas and Tarrant counties were collapsed for this geospatial analysis given that they are geographically side by side. The analyses are for three county areas (Figure 1). In 2014-2015, the weighted sample was $49 \%$ female; $54.8 \%$ Hispanic, $21.4 \%$ non-Hispanic White, $17.2 \%$ non-Hispanic Black; $6.6 \%$ Other race/ethnicities; $18.3 \%$ with family standard of living as just getting by to poor [8]. The University of Texas Health Science Center at Houston's Institutional Review board approved this study (\#HSC-SPH-13-0377).

\section{Measures}

The list of permitted tobacco retail outlets (TRO), was obtained

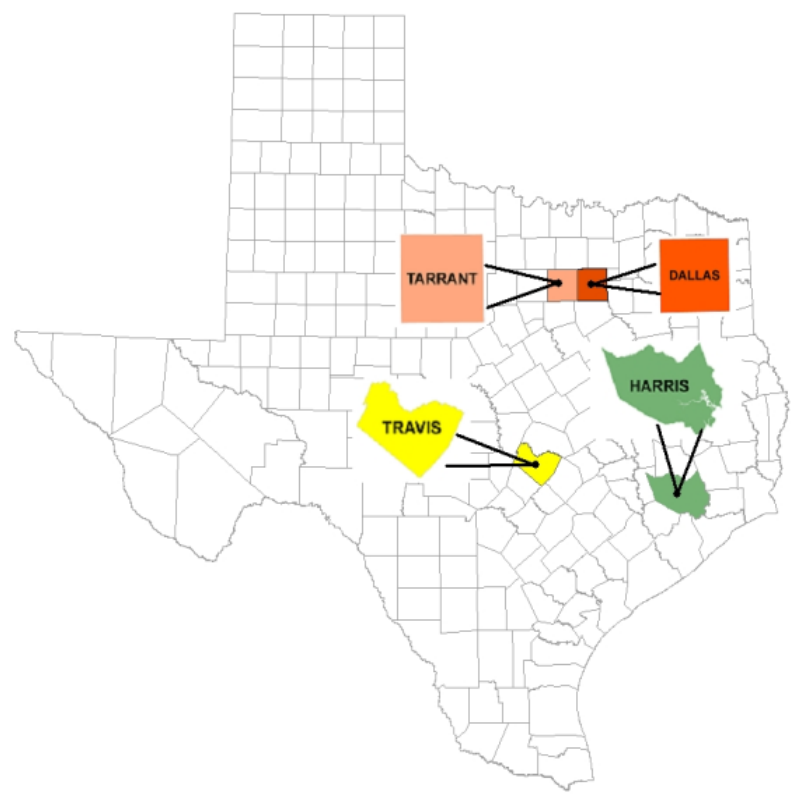

Figure 1: The analyses are for three county areas. in November 2014 from the Texas Comptroller of Public Accounts (2014) [18]. The number of TRO within a half-mile radius around each school served to identify two strata: schools without TRO and schools with one or more TRO. Twenty five percent of the participants were located in schools without TRO [8]. Students were identified as current cigarette users if they answered 'Yes' to the question 'Have you ever tried cigarette smoking, even one or two puffs?' and responded that the number of days were greater than 0 to the question 'During the past 30 days, on how many days did you smoke cigarettes?'. Students were identified as current e-cigarette users if they answered 'Yes' to the question 'Have you ever tried electronic cigarette, vape pen, or e-hookah, even one or two puffs?' and reported the number of days as greater than 0 in the question 'During the past 30 days, on how many days did you smoke electronic cigarette, vape pen, and e-hookah?'. Students were asked "During the past 30 days, how often have you visited the following places near your school?" for stores: "Gas station, convenience/corner stores", "Drug stores such as Walgreens" and "Grocery stores". If a student responded "never" to visiting all three stores, then he/she was classified as never visiting any of these stores near his/her school, otherwise he/she was classified as visiting at least one of the stores. If students visited any of these places, then they were asked "When you visited [stores], how often did you see [signs]?" with signs described as (i) marketing cigarettes, marketing electronic cigarettes, vape pens, or e-hookah", and (iii) "warning about the dangers of smoking (not including warnings on packages)". Responses were collapsed into two categories "never/not that I remember" versus "recall any signs marketing cigarettes", "recall any signs marketing e-cigarettes", and "recall any warning signs", respectively. Additional control variables included: sex, race/ethnicity, grade, family standard of living, and three school zip-code level characteristics from the 2014 American Community Survey 5 Year Estimates [19], covering 2010 to 2014, including (i) percentage of high school graduate or higher, (ii) the median household income in the past 12 months in 2014 inflation adjusted dollars, and (iii) the percent below poverty level for the population for whom poverty status is determined.

\section{Statistical analysis}

All analyses use sampling weights to account for the complex sampling design. Differences in sociodemographic characteristics for current use of cigarette and e-cigarette users were estimated using chisquare statistics. We applied a Bayesian structured additive regression model to carry out spatial analyses [20]. A spatial function was included by using the Markov random fields, known as the structured additive regression (STAR) model [21] with an intrinsic conditional autoregressive prior. The Markov chain Monte Carlo simulation method was used for estimating the unknown parameters in this model. One spatial model investigated if there was an association between the presence or absence of TRO near the schools and the prevalence of current use of cigarettes and another for e-cigarettes. An interaction of the spatial function with TRO was included after adjusting for sex, race/ethnicity, grade, family standard of living, reported visiting stores near the school during past 30 days, recalling signs marketing cigarettes (for the cigarette model) or recallin signs marketing e-cigarettes (for the e-cigarette model), recalling warning signs, the percentage of high school graduates or higher in the school zip code, the median household income in the school zip code, and the percent below poverty level from the school zip code. Each model was estimated for each study area. This is a total of three geospatial models for cigarette use and another three for e-cigarette use.

The regression model can be represented in the following way. 
In statistical terms, suppose the response $\mathrm{Y}_{\mathrm{ij}}$ represents current use of cigarettes. The subscriptions $(i, j)$ indicate the student index $i$ and the school index $j$. Equation 1 describes the STAR model building a Bayesian geoadditive logistic model framework.

$$
\operatorname{Logit}\left(Y_{i j}\right)=\alpha+\beta X_{i}+\gamma Z_{j}+\left(T R O_{j}\right) \times f_{\text {spat }}(j)
$$

where Logit(.) is a logit function for $\log \left[\mathrm{P}\left(\mathrm{Y}_{\mathrm{ij}}=1\right) /\left(1-\mathrm{P}\left(\mathrm{Y}_{\mathrm{ii}}=1\right)\right]\right.$, the unknown parameter $\alpha$ indicates a fixed intercept, $\beta$ identifies a $6 \times 1$ vector containing six unknown parameters for individual-level confounders $\mathbf{X}_{\mathbf{i}}$ (i.e., sex, race/ethnicity, grade, family standard of living, recalling marketing signs, recalling warning signs), $\gamma$ identifies a $3 \times 1$ vector containing three unknown parameters for socioeconomic status variables $\mathbf{Z}_{\mathbf{j}}$ (i.e., the percentage of high school graduate or higher, the median household income, and the percent below poverty level) from zip codes where school $j$ is located. TRO is a dummy variable of whether there is at least one TRO around school $j$, and it interacts with a spatial function $f_{\text {spat }}(j)$, which is the Markov random fields taking spatial autocorrelation into account [22,23]. Further, all estimated coefficients were weighted by the reciprocal of the number of students in each school. Adjusted odds ratios (OR) were calculated for $\mathbf{X}_{\mathrm{i}}$ and $\mathbf{Z}$ from exponential estimates of $\beta$ and $\gamma$. The spatial function generated a spatial estimate in each school. Those spatial estimates are transformed into relative risks (RR) of the presence of the TRO on the current use of cigarettes or e-cigarettes in a school compared to all schools. Then, for estimating whether the other non-selected schools have a potential risk of higher students' current use of cigarettes or e-cigarettes, we applied a univariate ordinary Kriging method to interpolate values among the rest of the schools in each county, and conducted a kriged map to show hot-spots inside the boundary of each study areas. All kriged values are presented in terms of the color patterns of HSV (hue, saturation and value) from blue color (Smaller RR) to red (Higher RR). Hence a hot-spot can be easily identified from those areas with a kriged RR shown in red color. We also add black dots in the maps representing the locations of participating schools.

TATAMS in 2014-2015 surveyed 3,907 students and 142 were excluded who were located on Bexar County. For the models regarding current use of cigarettes, 24 were excluded because they did not report their family standard of living or current use of cigarettes. For the models regarding current use of e-cigarettes, 21 students were excluded because they did not report their family standard of living or current use of e-cigarettes. Because of the low prevalence of current users of cigarettes in Harris county and visiting stores near schools during past 30 days, this covariate was excluded from this county model with the purpose to obtain convergence. This happened similarly for current use of cigarettes in Travis county and race/ethnicity that were excluded as covariates with the purpose of obtaining convergence in Travis county. Data management and demographic analyses were accomplished by SAS v9.4 (SAS Institute Inc., Cary). Geospatial analyses were implemented by R2BayesX package in R v3.2.4 and Spacestat 4.0. Maps were drawn by ArcGIS (ERSI) and Spacestat 4.0. We used a type I error level of 0.05

\section{Results}

This study included students from 32, 20 and 22 schools in Dallas/ Tarrant, Harris, and Travis counties, respectively. Table 1 provides descriptive statistics for current users and non-current users of cigarettes and e-cigarettes in the study areas. Current users of cigarettes or e-cigarettes were more likely to be $10^{\text {th }}$ graders and have a family standard of living as very well off, respectively. The influence of covariates on current use of cigarettes and e-cigarettes by each study area is shown in Table 2. In Harris and Travis counties, students in $8^{\text {th }}$ and $10^{\text {th }}$ grades had higher odds than $6^{\text {th }}$ grade students of current use of cigarettes. The adjusted odds of current use of cigarettes for students who reported that their families were just getting by or were poor as their standard of living in Dallas/Tarrant county were higher as compared to those living comfortably. In Dallas/Tarrant and Travis counties, students in $8^{\text {th }}$ and $10^{\text {th }}$ grades had higher odds than $6^{\text {th }}$ grade students of current use of e-cigarettes. In Harris and Travis counties, the odds of current use of e-cigarettes were higher among those who recalled sings marketing signs e-cigarette in stores around their school in comparison to those students who do not recall signs marketing signs of e-cigarettes in stores around their school, after adjusting for covariates.

Figure 2 shows the association of the geospatial presence of the TRO on current use of cigarettes (panel a) and e-cigarettes (panel b) by each study area, Dallas/Tarrant, Harris and Travis counties, respectively. The blue areas on the left of panel a indicate that there is not an association between the geospatial presence of the TRO and current use of cigarettes in Tarrant county. On the contrary, the red areas on the left of panel a indicate that there is an association in the geospatial presence of the TRO on current use of cigarette in the eastern area of Dallas county where there are five schools in that hot-spot. We observed an association in the geospatial presence of the TRO on current use of e-cigarettes in the entire Tarrant county, particularly in the north and northwestern areas (panel b). Two participating schools were located nearby the hot-spot of the geospatial presence of the TRO and current use of cigarettes in the southeastern area of Harris county (panel c). Panel d also shows that in eastern Harris county there is an association in the geospatial presence of the TRO and current use of e-cigarettes. Six study schools were surrounded by TRO in the hot-spot of current use of e-cigarette in the northeastern area of Harris county (panel $\mathrm{d}$ ). Panels e and $\mathrm{f}$ do not present a clear pattern of associations of the presence of TRO with current use of cigarettes or e-cigarettes in Travis county.

\section{Discussion}

To our knowledge this is the first study to report the geospatial association of the presence of tobacco retail outlets within a half-mile radius around schools with current use of e-cigarettes. Other studies have examined this relationship with cigarette smoking $[9,17]$. By design, the majority of the schools in this study $(75 \%)$ had at least one to TRO within a half-mile radius which represented the proportion of TRO in their sampling frame for each county [8]. Students in schools in hot-spots of Dallas/Tarrant and Harris counties, who had TRO around their schools, had higher RR of current use of cigarettes or e-cigarettes after adjusting for multiple covariates. This finding is intuitive and supports the hypothesis that tobacco use behavior is influenced by the density of tobacco retail outlets around where they live or study $[16,17]$. The easy access to the tobacco products, less retrieval cost and exposure to more brand promotions and/or tobacco advertising may be encouraging use [24] in these hot-spots identified. Policies and interventions that lead to the reduction in the number of TRO around the schools in the hot-spots may help in reducing the use of tobacco products by adolescents [25].

Exploring the potential for limiting the density and types of TRO, as well as increasing the distance from the TRO to the schools may be a plausible strategy to reduce the increasing prevalence of e-cigarette use [16]. The potential of such policies will need to be explored and evaluated. There are several policy research challenges 
Citation: Pérez A, Chien LC, Harrell MB, Pasch KE, Obinwa UC, et al. (2017) Geospatial Associations Between Tobacco Retail Outlets and Current Use of Cigarettes and e-Cigarettes among Youths in Texas. J Biom Biostat 8: 375. doi: 10.4172/2155-6180.1000375

Page 4 of 6

\begin{tabular}{|c|c|c|c|c|c|c|c|c|}
\hline \multirow[t]{4}{*}{ Variable } & \multicolumn{4}{|l|}{ Cigarette } & \multicolumn{4}{|l|}{ E-Cigarette } \\
\hline & \multicolumn{2}{|c|}{ Current user } & \multicolumn{2}{|c|}{ Non-current user } & \multicolumn{2}{|l|}{ Current user } & \multicolumn{2}{|c|}{ Non-current user } \\
\hline & \multicolumn{2}{|c|}{$n=80(N=14249)$} & \multicolumn{2}{|c|}{$n=3661(N=418014)$} & \multicolumn{2}{|c|}{$n=245(N=31126)$} & \multicolumn{2}{|c|}{$n=3499(N=401293)$} \\
\hline & $n(N)$ & $\%$ & $n(N)$ & $\%$ & $n(N)$ & $\%$ & $n(N)$ & $\%$ \\
\hline \multicolumn{9}{|l|}{ Sex } \\
\hline Boys & 41 (7159) & 50.2 & $1609(216363)$ & 51.8 & 134 (17018) & 54.7 & $1516(206610)$ & 51.5 \\
\hline Girls & 39 (7092) & 49.8 & $2052(201651)$ & 48.2 & $111(14108)$ & 45.3 & $1983(194683)$ & 48.5 \\
\hline \multicolumn{9}{|l|}{ Race/Ethnicity } \\
\hline Black & $11(2384)$ & 16.7 & $604(76273)$ & 18.2 & $46(4855)$ & 15.6 & 567 (73366) & 18.3 \\
\hline Hispanic & 43 (9179) & 64.4 & $1319(216850)$ & 51.9 & $113(18983)$ & 61.0 & $1256(207737)$ & 51.8 \\
\hline White/Other & $26(2685)$ & 18.9 & $1738(124891)$ & 29.9 & $86(7288)$ & 23.4 & $1676(120190)$ & 29.9 \\
\hline Grade & \multicolumn{4}{|l|}{ ** } & \multicolumn{4}{|l|}{ *** } \\
\hline 6th & $6(1208)$ & 8.5 & 1099 (139692) & 33.4 & 15 (2938) & 9.4 & $1093(138061)$ & 34.4 \\
\hline 8th & $17(3932)$ & 27.6 & $1217(140863)$ & 33.7 & $54(8612)$ & 27.7 & $1180(136348)$ & 33.9 \\
\hline 10th & 57 (9109) & 63.9 & $1345(137458)$ & 32.9 & 176 (19575) & 62.9 & $1226(126883)$ & 31.7 \\
\hline \multicolumn{9}{|c|}{ Tobacco Retail Outlets ${ }^{\star *}$} \\
\hline+1 & $57(12772)$ & 89.6 & $1831(105860)$ & 74.7 & $148(25023)$ & 80.4 & $1740(299922)$ & 74.7 \\
\hline 0 & $23(1477)$ & 10.4 & $1830(312154)$ & 25.3 & 97 (6103) & 19.6 & $1759(101370)$ & 25.3 \\
\hline \multicolumn{5}{|c|}{ Family's standard of living ${ }^{* * *}$} & \multicolumn{4}{|l|}{ ** } \\
\hline Living comfortably & $8(805)$ & 5.7 & 849 (86801) & 20.8 & $45(5228)$ & 16.8 & 813 (82732) & 20.6 \\
\hline Very well off & 44 (7865) & 55.2 & $2280(260783)$ & 62.4 & $140(17391)$ & 55.9 & $2182(250778)$ & 62.5 \\
\hline Just getting by-poor ${ }^{a}$ & 28 (5579) & 39.1 & 532 (70431) & 16.8 & $60(8506)$ & 27.3 & 504 (67783) & 16.9 \\
\hline \multicolumn{9}{|c|}{ During past 30 days visited stores near school } \\
\hline Yes & $76(14006)$ & 98.3 & $3600(412445)$ & 98.7 & $238(30498)$ & 98.0 & $3442(396147)$ & 98.7 \\
\hline No & $4(243)$ & 1.7 & $61(5569)$ & 1.3 & $7(628)$ & 2.0 & $57(5146)$ & 1.3 \\
\hline \multicolumn{9}{|c|}{ Recall any warning signs about the dangers of smoking } \\
\hline Yes & 37 (6449) & 45.3 & $2093(237640)$ & 56.8 & $136(16056)$ & 51.6 & $2001(228706)$ & 57.0 \\
\hline No & $43(7800)$ & 54.7 & $1568(180373)$ & 43.2 & 109 (15069) & 48.4 & $1498(172587)$ & 43.0 \\
\hline \multicolumn{5}{|c|}{ Recall any signs marketing cigarettes } & \multicolumn{4}{|c|}{ Recall any signs marketing e-cigarettes ${ }^{* *}$} \\
\hline Yes & $65(11962)$ & 83.9 & $3146(345128)$ & 82.6 & 156 (20878) & 67.1 & $1742(200482)$ & 50.0 \\
\hline No & $15(2287)$ & 16.1 & 515 (72886) & 17.4 & 89 (10248) & 32.9 & $1757(200811)$ & 50.0 \\
\hline
\end{tabular}

$\mathrm{n}=$ sample size, $\mathrm{N}=$ weighted sample size;

aFamily's standard of living as "just getting by", "nearly poor," or "poor."

Note: Italicized values indicates Statistical significance $\left({ }^{*} p<0.05,{ }^{* *} p<0.01,{ }^{* * *} p<0.0001\right)$.

Table 1: Summary statistics of current use of cigarettes and e-cigarettes in TATAMS in 2014-2015 overall counties.

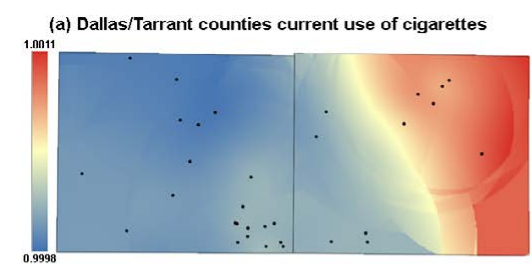

(c) Harris counties current use of cigarettes

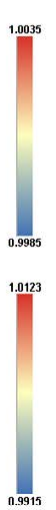

(e) Travis counties current use of cigarettes

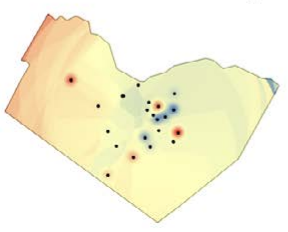

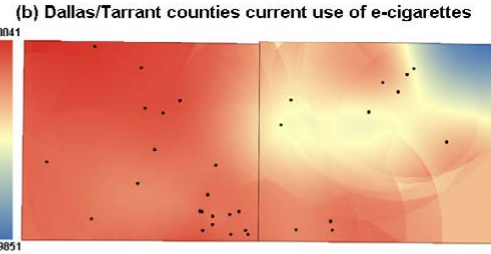

(d) Harris counties current use of $\theta$-cigarettes

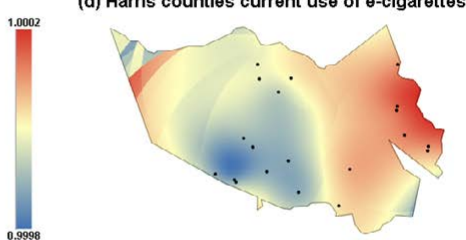

(f) Travis counties current use of e-cigarettes

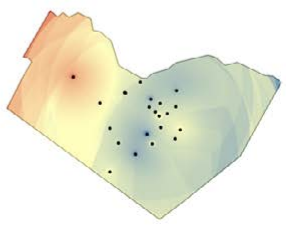

Figure 2: The association of the geospatial presence of the TRO on current use of cigarettes (panel a) and e-cigarettes (panel b) by each study area, Dallas/Tarrant, Harris and Travis counties. 
Citation: Pérez A, Chien LC, Harrell MB, Pasch KE, Obinwa UC, et al. (2017) Geospatial Associations Between Tobacco Retail Outlets and Current Use of Cigarettes and e-Cigarettes among Youths in Texas. J Biom Biostat 8: 375. doi: 10.4172/2155-6180.1000375

Page 5 of 6

\begin{tabular}{|c|c|c|c|c|c|c|}
\hline \multirow[b]{2}{*}{ Variable } & \multicolumn{2}{|l|}{ Dallas/Tarrant } & \multicolumn{2}{|l|}{ Harris } & \multicolumn{2}{|l|}{ Travis } \\
\hline & AOR $(95 \% \mathrm{Cl})$ & Sig & AOR $(95 \% \mathrm{Cl})$ & Sig & AOR $(95 \% \mathrm{Cl})$ & Sig \\
\hline \multicolumn{7}{|c|}{ Current Use of Cigarettes } \\
\hline \multicolumn{7}{|l|}{ Sex } \\
\hline Boys & $1.15(0.56-2.37)$ & & $1.45(0.28-7.42)$ & & $0.75(0.29-1.97)$ & \\
\hline Girls & 1 & & & & & \\
\hline \multicolumn{7}{|l|}{ Ethnicity } \\
\hline Black & 1 & & 1 & & NA & \\
\hline Hispanic & $2.04(0.66-6.36)$ & & $1.59(0.40-6.32)$ & & & \\
\hline White/Other & $2.44(0.77-7.66)$ & & $1.79(0.58-5.47)$ & & & \\
\hline \multicolumn{7}{|l|}{ Grade } \\
\hline $6^{\text {th }}$ & 1 & & & & & \\
\hline $8^{\text {th }}$ & $0.42(0.06-3.17)$ & & $3.45(1.51-7.89)$ & ** & $5.47(1.01-29.48)$ & ** \\
\hline $10^{\text {th }}$ & $3.18(0.91-11.06)$ & & $3.13(2.58-3.81)$ & ** & $12.85(2.029-81.36)$ & ** \\
\hline \multicolumn{7}{|c|}{ Family's standard of living } \\
\hline Living comfortably & 1 & & 1 & & 1 & \\
\hline Very well off & $2.22(0.48-10.21)$ & & $1.73(0.7-4.50)$ & & $1.81(0.38-8.73)$ & \\
\hline Just getting by-poor & $8.26(1.77-38.60)$ & ** & $1.97(0.32-12.08)$ & & $3.59(0.70-18.34)$ & \\
\hline \multicolumn{7}{|c|}{ Recall any signs marketing cigarettes } \\
\hline No & 1 & & 1 & & & \\
\hline Yes & $0.86(0.30-2.46)$ & & $1.56(0.29-8.48)$ & & $1.59(0.33-7.60)$ & \\
\hline \multicolumn{7}{|c|}{ Recall any warning signs about the dangers of smoking } \\
\hline No & 1 & & 1 & & 1 & \\
\hline Yes & $0.65(0.31-1.37)$ & & $1.45(1.00-2.09)$ & & $1.38(0.51-3.78)$ & \\
\hline \multicolumn{7}{|c|}{ Current use of e-cigarettes } \\
\hline \multicolumn{7}{|l|}{ Sex } \\
\hline Boys & $1.24(0.84-1.84)$ & & $0.69(0.45-1.01)$ & & $1.64(0.92-2.95)$ & \\
\hline Girls & 1 & & & & & \\
\hline \multicolumn{7}{|l|}{ Ethnicity } \\
\hline Black & 1 & & 1 & & 1 & \\
\hline Hispanic & $1.13(0.67-1.90)$ & & $0.89(0.52-1.50)$ & & $2.45(0.32-18.71)$ & \\
\hline White/Other & $1.58(0.93-2.66)$ & & $0.62(0.32-1.22)$ & & $4.95(0.62-39.43)$ & \\
\hline \multicolumn{7}{|l|}{ Grade } \\
\hline $6^{\text {th }}$ & 1 & & & & & \\
\hline $8^{\text {th }}$ & $4.62(1.57-13.57)$ & ** & $1.22(0.36-4.13)$ & & $4.95(1.56-15.76)$ & ** \\
\hline $10^{\text {th }}$ & $10.81(4.41-26.45)$ & ** & $2.83(0.95-8.40)$ & & $22.62(7.17-71.43)$ & ** \\
\hline \multicolumn{7}{|c|}{ Family's standard of living } \\
\hline Living comfortably & 1 & & 1 & & 1 & \\
\hline Very well off & $0.70(0.42-1.17)$ & & $1.12(0.62-2.03)$ & & $1.03(0.49-2.18)$ & \\
\hline Just getting by-poor ${ }^{a}$ & $1.32(0.75-2.33)$ & & $1.13(0.54-2.34)$ & & $0.99(0.41-2.39)$ & \\
\hline \multicolumn{7}{|c|}{ Recall any signs marketing e-cigarettes } \\
\hline No & 1 & & 1 & & & \\
\hline Yes & $1.31(0.88-1.96)$ & & $1.72(1.11-2.68)$ & ** & $2.35(1.22-4.55)$ & ** \\
\hline \multicolumn{7}{|c|}{ Recall any warning signs about the dangers of smoking } \\
\hline No & 1 & & 1 & & 1 & \\
\hline Yes & $0.97(0.66-1.42)$ & & $1.08(0.70-1.65)$ & & $1.42(0.78-2.58)$ & \\
\hline
\end{tabular}

Note: Italicized values indicates statistical significance $\left({ }^{*} p<0.05,{ }^{*} p<0.01, p<0.0001\right)$. Adjusted for during past 30 days visited stores near school, the percentage of high school graduate or higher in the school zip code, the median household income in the school zip code, and the percent below poverty level from the school zip code.

aFamily's standard of living as "just getting by", "nearly poor," or "poor."

AOR $(95 \% \mathrm{Cl})$, Adjusted odds ratios (OR) with 95\% credible interval (Cl).

Table 2: Adjusted odds ratio of linear predictors for current use of cigarettes and e-cigarettes by county.

that will need to be addressed in future studies [15]. First, is there an appropriate number of cigarette and e-cigarette advertisements per TRO that should be permitted around the schools?. Past studies have shown that there are more exterior cigarette ads near schools and more ads where kids shop [14,26], but to our knowledge we do not know of any study on e-cigarette ads. Second, the U.S. Food and Drug Administration (FDA) has been granted specific regulatory authority to restrict the manufacturing, distribution, and marketing of tobacco products [27]. Enforcing any FDA advertising regulations will have a significant number of challengers not only to understand how the states or counties implement such policies, but the crucial component of providing adequate and reliable scientific research that links TRO advertisements with tobacco use behaviors by adolescents. Third, the impact of these policies need to be evaluated. In California, for example, $31 \%$ of the TRO at the start of the intervention stopped marketing tobacco post-intervention [13], demonstrating that it is feasible to evaluate interventions at TRO. However, evaluating such 
Citation: Pérez A, Chien LC, Harrell MB, Pasch KE, Obinwa UC, et al. (2017) Geospatial Associations Between Tobacco Retail Outlets and Current Use of Cigarettes and e-Cigarettes among Youths in Texas. J Biom Biostat 8: 375. doi: 10.4172/2155-6180.1000375

interventions will need to be, like the current study, linked with tobacco use behaviors across time.

The strength of this study is the use of geospatial modeling to consider the geographic association of current use of cigarette and e-cigarette and presence of TRO near schools. The results of interpolation can provide further information to schools that were not selected at random, especially in Harris and Dallas/Tarrant counties. Some limitations existed in this study. First, schools were selected based on the sampling design of TATAMS and not by the geographic distribution of schools across the county, and as such, are not uniform. Second, some counties had some areas without enough data to support the findings, even after using kriging, such as the southeastern Dallas, western Harris, and eastern of Travis counties. Third, the number of TRO may vary over time, while our data cannot reflect the variation, we considered whether schools have at least one TRO reducing potential bias from varied TRO. The sample size for current use of cigarettes was not enough in Harris and Travis, causing insufficient data to estimate associations in youth in those populations.

\section{Conclusions}

The identification of hot-spots in the Texas counties, where the presence of TRO is associated with cigarette or e-cigarette use is important, as these findings support the potential need for regulation of TRO around the identified geospatial areas. More research on what constitutes a hot-spot is warranted.

\section{Acknowledgments}

The authors wish to thank data collector for their efforts during the survey and the tobacco retail outlets. We are also grateful to the school districts, schools, children and parents who participated in the study. We are grateful to all supporting staff at the Michael and Susan Dell Center of Healthy Living, The University of Texas Health Science Center at Houston-UTHealth, School of Public Health, Austin Campus for their indirect help with this project. This work was supported by the National Cancer Institute of the National Institutes of Health $(\mathrm{NIH})$ and the Center for Tobacco Products of the Food and Drug Administration (FDA) of the United States Department of Health and Human Services (grant number P50 CA180906). The content is solely the responsibility of the authors and does not necessarily represent the official views of the National Institutes of Health or the Food and Drug Administration.

\section{References}

1. Wipfli H, Samet JM (2016) One hundred years in the making the global tobacco epidemic. Annu Rev Public Health 37: 149-166.

2. US Department of Health and Human Services. The Health consequences of Smoking 50 years of progress a Report of the Surgeon General. Atlanta GA Centers for Disease Control and Prevention National Center for Chronic Disease Prevention and Health Promotion Office on Smoking and Health.

3. US Department of Health and Human Services. Preventing Tobacco Use among Youth and Young Adults a Report of the Surgeon General. Atlanta GA Centers for Disease Control and Prevention National Center for Chronic Disease Prevention and Health Promotion, Office on Smoking and Health.

4. US Department of Health and Human Services. E Cigarette Use Among Youth and Young Adults a Report from the Surgeon General. Atlanta GA Centers for Disease Control and Prevention National Center for Chronic Disease Prevention and Health Promotion Office on Smoking and Health.

5. Ordonez JE, Kleinschmidt KC, Forrester MB (2015) Electronic cigarette exposures reported to Texas poison centers. Nicotine Tob Res 17: 209-211.
6. Hyland A, Ambrose BK, Conway KP (2017) Design and methods of the Population Assessment of Tobacco and Health study. Tob Control 26: 371-378.

7. Kasza KA, Ambrose BK, Conway KP (2017) Tobacco-product use by adults and youths in the United States in 2013 and 2014. N Engl J Med 376: 342-353.

8. Pérez A, Harrell MB, Malkani RI (2017) Texas adolescent tobacco and marketing surveillance system's design. Tobacco Regulatory Science 3: 151-167.

9. Henriksen L, Schleicher NC, Feighery EC, Fortmann SP (2010) A longitudinal study of exposure to retail cigarette advertising and smoking initiation. Pediatrics 126: 232-238.

10. Centers for Disease Control Prevention (2002) Point-of-purchase tobacco environments and variation by store type United States 1999.MMWR 51: 184.

11. Feighery EC, Henriksen L, Wang Y, Schleicher NC, Fortmann SP (2006) An evaluation of four measures of adolescents exposure to cigarette marketing in stores. Nicotine Tob Res. 8: 751-759.

12. Nicksic NE, Harrell MB, Pérez A, Pasch KE, Perry CL (2017) Recall of e-cigarette advertisements and adolescent e-cigarette use. Tobacco Regulatory Science.

13. Coxe N, Webber W, Burkhart J (2014) Use of tobacco retail permitting to reduce youth access and exposure to tobacco in Santa Clara County, California. Prev Med 67: 46-50.

14. Luke DA, Ribisl KM, Smith C, Sorg AA (2011) Family smoking prevention and tobacco control act banning outdoor tobacco advertising near schools and playgrounds. Am J Prev Med 40: 295-302.

15. Myers AE, Hall MG, Isgett LF, RibisI KM (2015) A comparison of three policy approaches for tobacco retailer reduction. Prev Med 74: 67-73.

16. Henriksen L, Feighery EC, Schleicher NC (2008) Is adolescent smoking related to the density and proximity of tobacco outlets and retail cigarette advertising near schools? Prev Med 47: 210-214.

17. Scully M, McCarthy M, Zacher M (2013) Density of tobacco retail outlets near schools and smoking behavior among secondary school students. Aust $\mathrm{N} \mathrm{Z} \mathrm{J}$ Public Health 37: 574-578.

18. Texas Comptroller of Public Accounts. Window on State Government Published 2014.

19. United States Census Bureau. American Fact Finder advanced search on the American Community Survey. Published 2016.

20. Goovaerts P (1997) Geostatistics for natural resources evaluation. Oxford University Press on Demand.

21. Fahrmeir L, Lang S (2001). Bayesian inference for generalized additive mixed models based on markov random field priors. Applied Statistics 50: 201-220.

22. Kindermann R, Snell JL (1980) Markov random fields and their applications. Providence RI American Mathematical Society.

23. Besag J, York J, Mollie A (1991) Bayesian image restoration with two applications in spatial statistics. Ann Inst Stat Math 43: 1-59.

24. Schneider JE, Reid RJ, Peterson NA, Lowe JB, Hughey J (2005) Tobacco outlet density and demographics at the tract level of analysis in lowa implications for environmentally based prevention initiatives. Prev Sci 6: 319-325.

25. Fichtenberg CM, Glantz SA (2002) Youth access interventions do not affect youth smoking. Pediatrics109: 1088-1092.

26. Henriksen L, Feighery E, Schleicher N, Haladjian H, Fortmann S (2004) Reaching youth at the point of sale cigarette marketing is more prevalent in stores where adolescents shop frequently. Tobacco Control 13: 315-318.

27. Gostin LO (2009) FDA regulation of tobacco politics law and the public's health. JAMA302: 1459-1460. 